\title{
MECANISMO ANTILUTEOLÍTICO: FISIOLOGIA E ESTRATÉGIAS
}

TEIXEIRA, Pedro Paulo Maia ${ }^{1}$

Recebido em: 2009-10-03

Aprovado em: 2009-10-30

ISSUE DOI: $10.3738 / 1982.2278 .312$

Resumo: A morte embrionária na produção de ruminantes ainda é um grande empecilho, principalmente em programas de IATF e receptoras de embrião. Na fase inicial da gestação, denominada de período crítico, em onde ocorre mais de $70 \%$ dês perdas, Neste período ocorrem uma série de reações para que exista a adaptação fisiológica de prenha para não prenha, o reconhecimento materno da prenhez, em que o concepto deve sinalizar sua presença pela liberação de inteferon táu, a fim de inibir a descarga programada de prostaglandina 2 alfa. A progesterona produzida pelo corpo lúteo é um dos fatores que vai estabelece a ocitocina se liga a seu receptores estimulada pela ação dos receptores de estrógeno estimulando a produção de PGF2 $\alpha$ que causa luteólise. O IFN- $\tau$ produzido pelo concepto liga-se nas células endoteliais do endométrio impedindo a produção de PGF2 $\alpha$ e a luteólise. Para melhorar os índices de morte embrionária ser fazem necessária a criação de estratégias anti-luteolíticas, que se reduzam os níveis de estrógeno para minimizar o estimulo nos OTCR, controlando a liberação de PGF2 $\alpha$, retardando ou bloqueando a luteólise ou aumentandar a concentração de progesterona circulante neste mesmo período. Aumentar a concentração de $\mathrm{P}_{4}$, uso de hCG, ECG e GnRH, são estratégias para estimular o mecanismo de anti-luteólise, além de estratégias envolvendo utilização de dietas específicas entre outras.

Palavras-chave: Antiluteolíticas. Mecanismos e estratégias.

\section{MECHANISM ANTILUTEOLYTIC: PHYSIOLOGY AND STRATEGIES}

SUMMARY: Death in the production of ruminant embryo is still a major obstacle, especially in programs of IATF and recipients of embryo. In the initial stage of pregnancy, called the critical period, which occurs in more than $70 \%$ of losses, this time a series of reactions occur so that there is a physiological adjustment of pregnant to not pregnant, the maternal recognition of pregnancy in which the concept must signal its presence by inteferon release of tau to inhibit the programmed discharge of prostaglandin 2 alpha. The progesterone produced by the corpus luteum is one of the factors that go down to oxytocin binds to its receptors stimulated by the action of estrogen receptors in stimulating the production of PGF $2 \alpha$ to cause luteolysis. The IFN- $\tau$ produced by the concept binds to endothelial cells in the endometrium prevents the production of PGF2 $\alpha$ and luteolysis. To improve the rates of embryo death is necessary to make development of anti-luteolíticas, to reduce the levels of estrogen to minimize the stimulus in OTCR, controlling the release of PGF2 $\alpha$, slowing or blocking the luteolysis aumentandar or the concentration of circulating progesterone this same period. Increasing the concentration of $\mathrm{P} 4$, use of $\mathrm{hCG}, \mathrm{GnRH}$ and $\mathrm{ECG}$, are strategies to stimulate the mechanism of anti-luteolysis, and strategies involving use of specific diets among others.

Keywords: Antiluteolytic. Mechanisms and strategies.

1 Médico Veterinário Graduado na Universidade Federal Rural da Amazônia. Mestrando do Programa de Cirurgia Veterinária - UNESP, Departamento de Obstetrícia e Reprodução animal FCAV/UNESP

Atua na área de Reprodução Animal, Produção de ruminantes com ênfase em Ovinos e Caprinos. 


\section{MECANISMO ANTILUTEOLÍTICO: FISIOLOGÍA Y ESTRATEGIAS}

RESUMEN: La muerte de embriones de rumiantes en la producción es todavía un obstáculo importante, especialmente en los programas de ITF y de los beneficiarios de embriones. En la etapa temprana del embarazo, el llamado período crítico, que se produce en más de $70 \%$ des pérdidas ocurren durante este período una serie de reacciones de manera que hay una adaptación fisiológica de las mujeres embarazadas no embarazadas, el reconocimiento materno del embarazo en el que el feto debe demostrar su presencia por la liberación de tau inteferon para inhibir la aprobación de la gestión programada de la prostaglandina 2 alfa. La progesterona producida por el cuerpo lúteo es uno de los factores que bajan la oxitocina se une a sus receptores estimulados por la acción del estrógeno, estimulando la producción de PGF2 $\alpha$ que causa luteólisis. IFN- $\tau$ producida por el feto se une las células endoteliales del endometrio impidiendo la producción de PGF2 $\alpha$ y luteólisis. Para mejorar las tasas de muerte de embriones necesarios para la creación de estrategias de lucha contra luteolítico, que reducen los niveles de estrógeno para minimizar el OTCR estímulo en el control de la liberación de PGF2 $\alpha$, la ralentización o el bloqueo de luteólisis y aumentar así la concentración de la progesterona circulante este mismo período. El aumento de la concentración de P4, el uso de hCG, GnRH y ECG, son estrategias para estimular el mecanismo de lucha contra la luteólisis, así como las estrategias que impliquen el uso de dietas específicas y otros.

Palabras clave: Antiluteolíticas. Los mecanismos y estrategias.

\section{INTRODUÇÃO}

A morte embrionária refere-se a perdas no período da fertilização até a completa diferenciação dos tecidos, sendo nos bovinos, período que compreende até os 42 dias de prenhez (DUNNE et al, 2000). A mortalidade embrionária (ME) pode ter um impacto bastante significativo sobre a eficiência reprodutiva de um rebanho, representando uma importante perda econômica na produção de bovinos (FLINT et $a l$, 1990) e ovinos (RIBEIRO et al, 2002) sendo que $70 \%$ das mortes embrionárias ocorrem por fatores não infecciosos, assim verificando a importância do reconhecimento materno fetal e do mecanismo anti-luteolítico, e ressaltando a existência de um "período critico" que é o período de ajuste do estado de não prenha para prenha, que na vaca ocorre entre 15 a 19 dias após o estro (CRISTHIANSON et al, 1992; RIBEIRO et al, 2002).

Pelo alto índice de morte embrionária, devido falhas fisiológicas no mecanismo de anti-luteólise, principalmente em protocolos de inseminação artificial em tempo fixo (IATF) e em receptoras de embrião provenientes transferência de produção de embriões in vitro (PIV) e in vivo, estimulando-se o estudo e a criação de estratégias anti-luteolíticas. (SANTOS et al, 2004). 


\section{MECANISMO ANTI-LUTEOLÍTICO}

Até o período em que ocorre o reconhecimento materno da prenhez (15 a 19 dias em fêmeas bovinas) a fisiologia uterina não apresenta mudanças. No entanto após esse momento o concepto deve sinalizar sua presença através de uma cadeia de reações a fim de inibir a produção pré-programanda de prostaglandina $2 \alpha$ (PGF2 $\alpha$ ) no endométrio, evitando a regressão do corpo lúteo, estabelecendo o mecanismo anti-luteolítico fisiológico (BINELLI et al, 2001).

A progesterona $\left(\mathrm{P}_{4}\right)$ produzida pelo $\mathrm{CL}$ é um dos fatores que vai estabelecer a manutenção da prenhez, no entanto também desencadeia a formação de fatores luteolíticos (Rodríguez, 2001). Pelos dias 10 a 15 do ciclo estral começam a diminuir o número de receptores de $\mathrm{P}_{4}$ no útero, começam a aumentar os receptores de estrógeno (ER), sendo que estes influenciam a expressão dos receptores de ocitocina (OTR), que vão influenciar diretamente na produção de PGF2 $\alpha$ (OLIVERA, 2006). No entanto a P4 no período critico diminui a afinidade da ocitocina (OT) com seus receptores (GRAZZINI et al. 1998).

A OT, produzida no hipotálamo e secretada pela hipófise, se liga nos OTR, estimulando a clivagem do ácido araquidônico (AA) a partir da fosfolipase C (PLC), esta ativando a fosfolipase A2 $\left(\mathrm{PLA}_{2}\right)$. Intervindo nessa reação o inositol trifosfato $\left(\mathrm{IP}_{3}\right)$, que estimula a liberação de íons cálcio $\left(\mathrm{Ca}^{++}\right)$e o diacilglicerol (DAG) que ativa a proteína kinase $\mathrm{C}(\mathrm{PKC})$, que em presença do $\mathrm{Ca}^{++}$estimula a $\mathrm{PLA}_{2}$ para a liberação do AA dos depósitos fosfolipídicos das células endometriais epiteliais (ROBERTS et al, 1999; LAMMING et al, 1995).

A transformação do AA em PGF2 $\alpha$ é regularizada pela isoforma da Ciclooxigenase 2 (COX2), a prostaglandina sintetase (BURGESS et al. 1990), mas da transformação do AA em PGF2 $\alpha$ ocorrem diversas reações. Inicialmente por adição de oxigênio na molécula de AA pela COX2 ela se converte em prostaglandina $\mathrm{G}_{2}$ $\left(\mathrm{PGG}_{2}\right)$, que por sua vez, pela atividade peroxidase da enzima bifuncional a $\mathrm{PGG}_{2}$ transforma-se em $\mathrm{PGH}_{2}$, que pela ação de enzimas específicas transforma-se em PGF2 $\alpha$ (NELSON e COX, 2002). É suposto que para que ocorra luteólise, o CL deve ser exposto à aproximadamente cinco a oito pulsos de PGF2 $\alpha$ com intervalos de seis a oito horas. Isso ocorre cada vez que a OT se liga ao OTR, desencadeando a cascata de produção do PGF2 $\alpha$ (RODRÍGUEZ, 2001). 
O aumento dos níveis de secreção de progesterona produzido pelo corpo lúteo promove a inibição dos níveis de receptores de ocitocina pouco antes da luteólise. Este processo se inicia durante a fase lúteal com a diminuição de receptores de ocitocina que não estimula ação da PGF2 $\alpha$ luteolítica ( MANN; HARESIGN, 2001).

\section{AÇÃO DO INF- $\tau$}

A fim de impedir a formação do PGF2 $\alpha$ e a luteólise, o concepto começa a produzir INF- $\tau$, nas suas células mononucleares do trofoectoderma, e por uma ação parácrina ligam-se as células endoteliais do endométrio, ligando-se aos seus receptores, o que promove um bloqueio no RNAm que codifica o gene dos ER e a expressão do gene para OTR, impedindo assim o desencadeamento do mecanismo endometrial luteolítico, no entanto o INF- $\tau$, não inibe a produção basal de PGF2 $\alpha$ (CHARPIGNY et al., 1997).

Por outro lado ao se ligar nos seus receptores o IFN- $\tau$ induz a via de transcrição citoplasmática, proteínas que ativam fosforilação intracelular forma um complexo que funciona como um mensageiro que ativam transdutores de sinais ativadores de transcrição (STAT) e elementos reguladores de interferon (IRE) que se liga a elementos de resposta estimulados por interferon (ISRE) nos genes que o possuem (DARNELL, 1997). Estes mandam uma mensagem do núcleo celular na forma de mediadores protéicos que inibir em um ou várias etapas a produção de PGF2 $\alpha$ em várias (RODRÍGUEZ, 2001).

Esse mecanismo ainda não é bem esclarecido, mas estudos experimentais, usando genes recombinantes de IFN- $\tau$, in vitro tentam estabelecer detalhadamente essas reações (ROBERTS et al.,1992; THATCHER et al, 1997), em ovinos o INF- $\tau$ produzido pelo embrião age de maneira parácrina nas células endometriais bloqueando a transcrição de genes para OCTR e ER (LAMMING et al, 1995), acreditando que através da inibição dos ER, não ocorra a regulação positiva nos OTR, com isso não promovendo a liberação PGF2 $\alpha$ (SPENCER et al, 1995).

Já em bovinos a relação entre os ER e OTR ainda não são bem esclarecidas, sendo que o ITF- $\tau$ pode agir diretamente nos OTR (KIMMISNS; MACLAREN, 2001; ROBINSON et al. 2001), já que a região promotora de genes para OTR contém um ISRE onde se ligam fatores regulatórios de interferon (IRF)-1 e -2 
(BATHAGATE et al, 1998). Também se supõe que o IFN- $\tau$ induza a síntese de proteína de reação cruzada com a ubiquitina (UCRP), degradando os proteossomos, sugerindo que possa atuar intensificando a degradação de PKC (Schafer-Somi, 2003). Ainda especula-se que o IFN- $\tau$ regule negativamente a expressão das enzimas prostaglandina $\mathrm{F}_{2}$ sintetase $\left(\mathrm{PGF}_{2} \mathrm{~S}\right)$ e prostagladina cetoredutase (9K-PGR), prevenindo a produção de PGF2 $\alpha$ (ASSELIN; FORTIER, 2000).

Propõe-se, ainda que o IFN- $\tau$ também exerce um efeito antiluteolítico incrementando os níveis de ácido linoléico, o qual inibe por ação da COX2 na formação do AA, alterando a formação de PGF2 $\alpha$ (RODRIGUES, 2001).

Outros trabalhos tentam esclarecer detalhadamente o mecanismo de antiluteólise mensurando proteínas in vitro e in vivo, entre elas o IFN- $\tau$, ou mesmo a expressão de RNAm em tecidos e células (EALY et al, 2004). Com a identificação do RNAm em células produtoras de IFN- $\tau$ verificou-se que a uma abundancia na transcrição com relação ao alongamento embrionário (DEMMERS et al, 2001), enquanto também verificou-se uma correlação positiva entre o tamanho do trofoblasto (BERTOLINI et al, 2002) e o crescimento do mesmo (ROBINSON et al 2006) com a expressão transcrição do IFN- $\tau$.

Métodos de identificação de proteínas utilizando anticorpos específicos, no caso IFN- $\tau$ bovino e ovino (bIFN- $\tau$ e oIFN- $\tau$ ), para dosar os níveis desta proteína em cada dia do período crítico da gestação para cada espécie (TAKAHASHi et al, 2004).

\section{ESTRATÉGIA ANTI-LUTEOLÍTICAS}

Pelo alto índice de morte embrionária, devido falhas fisiológicas no mecanismo de anti-luteólise, principalmente em protocolos de inseminação artificial em tempo fixo (IATF) e em receptoras de embrião provenientes transferência de produção de embriões in vitro (PIV) e in vivo, estimulando-se o estudo e a criação de estratégias anti-luteolíticas. (SANTOS et al, 2004).

Existem várias abordagens para tentar evitar a morte embrionária no período crítico. Umas destas é, com a finalidade de prolongar fase luteínica foi utilizada administração exógena de fluido folicular, depledado de esteróides 
(incluindo o $\mathrm{E}_{2}$ ), que retardou a luteólise e suprimindo o crescimento folicular, prolongando a fase luteínica. Podendo especular que a inibina cause esse efeito no processo (SALFEN et al, 1999).

Outra estratégia anti-luteolítica também utilizada é a remoção mecânica do folículo dominante assim diminuindo a produção de $\mathrm{E}_{2} \mathrm{e}$ aumentando a produção de $\mathrm{P}_{4}$ (MACHADO et al, 2005).

Também com essa finalidade realisou-se estudos envolvendo uma buserelina, composto nonapeptídico agonista de $\mathrm{GnRH}$, com aproximadamente 40 vezes a potência do GnRH endógeno (STEVEN, 1983), capaz de alterar a função ovariana, modulando as ondas de crescimento folicular, prolongando a vida útil do corpo lúteo e a duração do ciclo estral (MILVAE et al, 1984; TWAGIRAMUNGU et al, 1992). O efeito primário do $\mathrm{GnRH}$ é estimular a síntese e a liberação do hormônio luteinizante (LH) da hipófise anterior, resultando também na síntese e/ou liberação, de forma menos pronunciada, do hormônio folículo estimulante (KALTENBACH et al, 1974; Steven, 1983). Porém não se observou efeito da utilização de buserelina sobre o percentual de gestação de receptoras de embrião bovino, mas $\mathrm{O}$ uso de uma única dose de buserelina aumentou os níveis plasmáticos de progesterona nas receptoras gestantes do grupo tratado em comparação às do grupo controle. (GALIMBERTI et al, 2001).

Estudos vinculados a nutrição para estimular o mecanismo anti-luteolítico, verificaram que dietas a base de gordura amarela e gordura derivada de peixe estimulam esse mecanismo. Quando ingeridas essas gorduras levam ao aumento da concentração do ácido linoléico, e este compete com o AA, formando outras prostaglandinas e diminuindo a formação de PGF2 $\alpha$ (MAGGIONi et al, 2008).

Porém mais simplesmente, com essa finalidade elaboraram-se estratégia em que se reduzem os níveis de estrógeno circulantes na fase luteínica e no período crítico, a fim de minimizar o estimulo nos OTCR, controlando a liberação de PGF2 $\alpha$, retardando ou bloqueando a luteólise ou aumentandar a concentração de progesterona circulante neste mesmo período, para estimular o reconhecimento materno-fetal (BINELLI et al, 2001). Enfatizando o papel da especial da progesterona produzida pelo corpo lúteo no controle do meio uterino e na nutrição do embrião.

Uma dessas estratégias para otimizar o mecanismo anti-luteolítico é a utilização de fármacos que estimulem o aumento dos níveis de progesterona 
(MANN et al, 1999). Com esse objetivo destaca-se o uso de hCG entre os dias 4 e 7 pós estro, o qual induz a formação de corpos lúteos acessório, aumento nas concentrações plasmáticas de progesterona (MARQUES, 2002; SANTOS et al, 2001). Com o mesmo intuito utiliza-se o ECG, mas também estimulação da liberação de LH, formando CL maiores, na tentativa de aumentar a concentração de $\mathrm{P}_{4}$ (TOVÍO et al, 2008). Também verificaram que vacas tratadas com 3000 UI de hCG no $5^{\circ}$ dia e depois com PGF $2 \alpha$ no $12^{\circ}$ dia após o estro mostrando luteólise incompleta, além de suprimir a o crescimento do folículo dominante, devido à maiores concentrações de progesterona que diminuiu a secreção de LH.

Também se utilizou para prolongar a fase luteínica e retardar o surgimento de maiores de 9mm é o uso de GnRH, entre os dias 11 e 13 (Peters, 1996).

Com a finalidade essa finalidade se utilizou tratamento com $\mathrm{GnRH}, \mathrm{LH}$, hCG e implantes de $\mathrm{P}_{4}$, em vacas e búfalas, alem do uso de flumexin megumine em recptoras de embrião, a fim de aumentar os níveis de progesterona e interferir na formação da PGF2 $\alpha$. (CAMPANILE et al, 2007; NISHIGA et al, 2002).

\section{CONSIDERAÇÕES FINAIS}

A morte embrionária no período crítico ainda é um grande empecilho na criação de ruminantes, e o estudo do mecanismo de anti-luteólise deve ser bem estudado para verificar falhas na produção, principalmente no uso de IATF e em receptoras de embrião, ressaltando a importância de cada vez mais estabelecer estratégias anti-luteolíticas.

\section{REFERÊNCIAS}

ASSELIN, E.; FORTIER, M.A. Detection and regulation of the messenger for a putative bovine endometrial 9-keto-prtostaglandin E2 reductase: effect of oxytocin and interferon-tau. Biol reprod. v. 62, p. 125 - 131. 2000.

BATHAGATE, R.A.D.; TILMANN, G.; IVELL, R. Molecular mechanism of the bovine oxytocin receptor gene regulation. Biol reprod. v. 58. suple. 160. 1998. 
BERTOLINI, M. et al. Growth, development and gene expression by in vivo and in vitro-produced day 7 and 16 bovine embryos. Mol reprod devel. v. 63. p. 318-328. 2002.

BINELLI, M. et al. Antiluteolytic strategies to improve fertility in cattle. Theriogenology. v.56, n.9, p.1451-1463, 2001.

BURGESS, K. et al. Effect of oxytocin and estradiol on uterine prostaglandin release in nonpregnant and early pregnant ewes. Biol reprod. v. 42, p. 822-833. 1990.

CAMPANILE, G.et al. Corpus luteum and embryonic mortality in buffaloes treated with a GnRH agonist, hCG and progesterone. Theriogenology. v. 67, p.1393-1398. 2007.

CHARPIGNY, G. et al. Cyclooxygenase- 2 unlike cyclooxygenase- 1 is highly expressed in ovine embryos during the implantation period. Biol reprod. v.57 p.1032-1040. 1997.

CRISTHIANSON, W.T. Stilbirths, mummies, abortions and errly embryonic death. The veterinary clinics of North America, food animal practice. v.8, p. 623-639, 1992.

DARNELL, J.E. STATs and gene regulation. Science. v. 277, p. 1630-1635, 1997.

DEMMERS, K.J.; DERECKA, K.; FLINT, A. Trophoblast interferon and pregnancy. Reprodution. v. 121. p. 41-49. 2001.

DUNNE, L.D.; DISKIN, M.G.; SREENAN, J.M. Embryo and foetal loss in beef heifers between day 14 of gestation and full term. Animal reproduction science. $v$. 58, n.1, p.39-44. 2000.

EALY, A.D. et al. Identification of interferon-T isoforms expressed by the periimplantation goat (Capra hircus) conceptus. Dom anim endocrin. v. 27. p. 39-49. 2004.

FLINT, A.P.; HEARN, J.P.; MICHAEL, A.E. The maternal recognition of pregnancy in mammals. Journal zoology. v.221, p.327-341, 1990.

GALIMBERTI, A.M. et al. Taxa de gestação e níveis plasmáticos de progesterona, em receptoras de embrião bovino, tratadas com buserelina após a inovulação. Rev. bras. zootec. v.30, n.2 Viçosa Mar./Apr. 2001.

KALTENBACH, C.C., DUNN, T.G., KISER, T.E. et al. Release of FSH and LH in beef heifers by synthetic gonadotrophin releasing hormone. J. Anim. Sci., v.38, n.2, p.357-362, 1974.

KIMMISNS, S.; MACLAREN, L.A. Oestrous cycle and pregnancy effects on the distribution of estrogen and progesterone receptors in bovine endometrium. Placenta. v. 22. p. 742-748, 2001. 
LAMMING, G.E. et al. Local actions of trophoblast interferons in suppression of the development of oxytocin and oestradiol receptors in ovine endometrium. Journal of reproduction and fertility. v.105, p. 165-175. 1995.

MACHADO, R. A Remoção do folículo dominante como estratégia antiluteolítica em bovinos. 2005, 200f. Tese (Doutorado). Universidade de São Paulo.

MAGGIONI, D., ROTTA, P.P; ITO, R.H. et al. Efeito da nutrição sobre a reprodução de ruminantes: uma revisão. PUBVET, v.2, n.11, mar3, 2008.

MARQUES, M.O. Ultra-sonografia ovarian, concentração plasmática de progesterone e taxa de concpção em novilhas receptoras de embrião submetidas a diferentes tratamentos no dia 7 do ciclo estral. 78f. 2002. Universidade de São Paulo.

MILVAE, R.A; MURPHY, B.D., HANSEL, W. Prolongation of bovine estrous cycle with a gonadotropin- releasing hormone analog. Biol. reprod., v.31, p.664670, 1984.

NELSON, D.L.; COX, M.M. Princípios da bioquímica. Rio de Janeiro: Sarvier. 3.ed. 2002. $975 \mathrm{p}$.

NISHIGAI, M.et al. Improvement of pregnancy rate in Japanese Black cows by administration of hCG to recipients of transferred frozen - thawed embryos. Theriogenology. v. 58, p. 1597-606. 2002.

OLIVERA, M. Gestación. en galina: reproducción de animales domésticos.

México: Limusa; 2006.

PETERS, A.R. Embryo mortality in cow. Animal breeding abstracts. v.64, p.587598, 1996.

RIBEIRO, L.A.O.; GREGORY, R.M.; MATTOS, R.C. Prenhez em rebanhos ovinos do Rio Grande do Sul, Brasil. Ciência rural, v. 32, n. 4, 2002.

ROBERTS, R.M.; CROSS, J.C.; LEAMAN, D.W. Interferons as hormones of pregnancy. Endocr Rev. v. 13. p. 432-452. 1992.

ROBERTS, R.M. et al. Trophoblast interferons. Placenta. v. 20, p.259-264. 1999.

ROBINSON, R.S. et al. In vivo expression of interferon-tau mRNA by the embryonic trophoblast and uterine concentrations of interferon-tau in during early pregnancy in the cow. Mol reprod devel. v. 73. p. 470-474.2006.

RODRÍGUEZ, J. Mecanismos para el reconocimiento materno de la preñez. In: MARACAIBO, G.C. (ed.) Reproducción bovina. Venezuela: Fundación GIRARZ, 2001.

SALFEN, B.E. et al. Effects of the presence of a dominant follicle and exogenous estradiol on the duration of the luteal phase of the bovine estrous cycles. Journal of dairy scince. v.85, p. 367, 1999. 
SANTOS, J.E.P. et al. Efefectes of hCG on luteal function and reproductive performance of high producing lactating Holstein dairy cows. Journal of animal science. v. 79, p. 2881-2894, 2001.

SANTOS, J.E.P. et al. The effect of embryonic death rates in cattle on the efficacy of estrus synchronization programs. Animal reproduction science. v. 82-83, p. 513-535, 2004.

SCHAFER-SOMI, S. Cytokines during early pregnancy of mammals: a review. Anim reprod sci. v. 75, p. 73-94, 2003.

SPENCER, T.E.; BAZER, F.W. Temporal and special alterations in uterine estrogen receptor and pregnancy in the ewe. Biol reprod. v. 53, p. 1527-1543, 1995.

STEVEN, J.O. Clinical uses of luteinizing hormone-releasing hormone. Fertility and sterility, v. 39, n.5, p.577-590, 1983.

TAKAHASHI, H. et al. Establishment of a specific radioimmunoassay for bovine interferon tau. Therio. v. 63, n.4, p. 1058-60, 2004.

THATCHER, W.W. et al. Antiluteolytic signals between of the conceptus and endometrium. Therio. v. 47, p. 140, 1997.

TOVÍO, N.L.; DUICA, A.A.; GRAJALES, H.L. Desarrollo embrionario y estrategias antiluteoliticas hormonales en programas de transplante de embriones bovinos. Rev.MVZ Córdoba. v. 13, n.1, p.1240-1251, 2008.

TWAGIRAMUNGU, H. et al. Synchronization of estrus and fertility in beef cattle with two injections of buserelin and prostaglandin. Theriogenology, v. 38, p.11311144, 1992. 